\title{
Fundamental Open Questions on Engineering of "Super" Hydrogen Sorption in Graphite Nanofibers: Relevance for Clean Energy Applications
}

\author{
Yury S. Nechaev ${ }^{*}$, Alp Yürüm², Adem Tekin³, Nilgün Karatepe Yavuz ${ }^{4}$, \\ Yuda Yürüm ${ }^{5}$, T. Nejat Veziroglu 6 \\ ${ }^{1}$ Bardin Institute for Ferrous Metallurgy, Moscow, Russia \\ ${ }^{2}$ Nanotechnology Research and Application Center, Sabanci University, Istanbul, Turkey \\ ${ }^{3}$ Informatics Institute, Istanbul Technical University, Istanbul, Turkey \\ ${ }^{4}$ Energy Institute, Istanbul Technical University, Istanbul, Turkey \\ ${ }^{5}$ Faculty of Engineering and Natural Sciences, Sabanci University, Istanbul, Turkey \\ ${ }^{6}$ International Association for Hydrogen Energy, Miami, USA \\ Email: ${ }^{*}$ Yuri1939@inbox.ru
}

Received 15 September 2014; revised 31 October 2014; accepted 16 November 2014

Copyright (C) 2014 by authors and Scientific Research Publishing Inc.

This work is licensed under the Creative Commons Attribution International License (CC BY).

http://creativecommons.org/licenses/by/4.0/

\section{Abstract}

Herein, some fundamental open questions on engineering of "super" hydrogen sorption (storage) in carbonaceous nanomaterials are considered, namely: 1) on thermodynamic stability and related characteristics of some hydrogenated graphene layers nanostructures: relevance to the hydrogen storage problem; 2) determination of thermodynamic characteristics of graphene hydrides; 3) a treatment and interpretation of some recent STM, STS, HREELS/LEED, PES, ARPS and Raman spectroscopy data on hydrogensorbtion with epitaxial graphenes; 4) on the physics of intercalation of hydrogen into surface graphene-like nanoblisters in pyrolytic graphite and epitaxial graphenes; 5) on the physics of the elastic and plastic deformation of graphene walls in hydrogenated graphite nanofibers; 6) on the physics of engineering of "super" hydrogen sorption (storage) in carbonaceous nanomaterials, in the light of analysis of the Rodriguez-Baker extraordinary data and some others. These fundamental open questions may be solved within several years.

\section{Keywords}

Hydrogen “Super” Sorption (Storage), Graphenes, Carbon Nanotubes, Graphite Nanofibers,

\footnotetext{
${ }^{*}$ Corresponding author.
}

How to cite this paper: Nechaev, Y.S., Yürüm, A., Tekin, A., Yavuz, N.K., Yürüm, Y. and Veziroglu, T.N. (2014) Fundamental Open Questions on Engineering of "Super" Hydrogen Sorption in Graphite Nanofibers: Relevance for Clean Energy Applications. American Journal of Analytical Chemistry, 5, 1151-1165. http://dx.doi.org/10.4236/ajac.2014.516122 


\section{A Breakthrough Hydrogen Storage Nanotecnology, Clean Energy Applications}

\section{Introduction}

Hydrogen is currently one of the most promising "green" fuels, owing to the fact that its gravimetric (mass) energy density of $142 \mathrm{MJ} / \mathrm{kg}$ (39.5 kWh/kg), (Figure 1, [1]) exceeds that of petroleum (oil) by a factor of three and that the product of its combustion is water vapor. On the other hand, the volumetric (volume) energy density of molecular gaseous hydrogen at 1 bar pressure is lower by several orders than that of oil (Figure 1, [1]), but it can exceed the oil quantity at megabar pressures (Figure 1, [1]-[3]). In light of this, the issue of finding systems and materials for a compact and energy efficient hydrogen storage assumes a primary importance. The known data on volumetric (volume) and gravimetric (mass) energy densities for different energy carriers [1] are shown in Figure 1. The additional symbol (the red circle) corresponds to the analytical data [2] [3] on the molecular solid hydrogen intercalated into the hydrogenated graphite nanofibers (GNFs); those are related to the extraordinary data [4]-[12] (being under consideration in this paper). As is noted in a number of studies, for instance in the recent review [13] [14], hydrogen-based fuel cells are promising solutions for the efficient and clean delivery of electricity. Since hydrogen is an energy carrier, a key step for the development of a reliable hydrogen-based technology requires solving the issue of efficient storage and transport of hydrogen. During the last few decades several proposals based on the design of advanced materials such as metal hydrides and carbon structures have been made to overcome the limitations of the conventional solution of compressing or liquefying of hydrogen in tanks.

Nevertheless, none of the proposed systems, with the exception of the nobody reproduced extraordinary experimental data [4]-[12] and the related analytical data [2] [3], are currently offering the required performances for the on-board hydrogen storage in fuel-cell-powered electrical vehicles [15] [16]. The performances are usually formulated in terms of hydrogen storage gravimetric (mass) and volumetric (volume) capacities (Figure 2, [17]) and control of adsorption/desorption processes, particularly, relevance to so called "reversibility" of the stored hydrogen. Therefore the problem of hydrogen efficient storage remains so far unsolved and it continues to represent a significant bottleneck to the advancement and proliferation of fuel cell and hydrogen technologies [1] [13]-[19].

It is shown [17], with regards to the known achievements, that the US Department of Energy (DOE) targets for the on-board hydrogen storage systems in fuel-cell-powered vehicles [15], relevant to gravimetric (mass) and

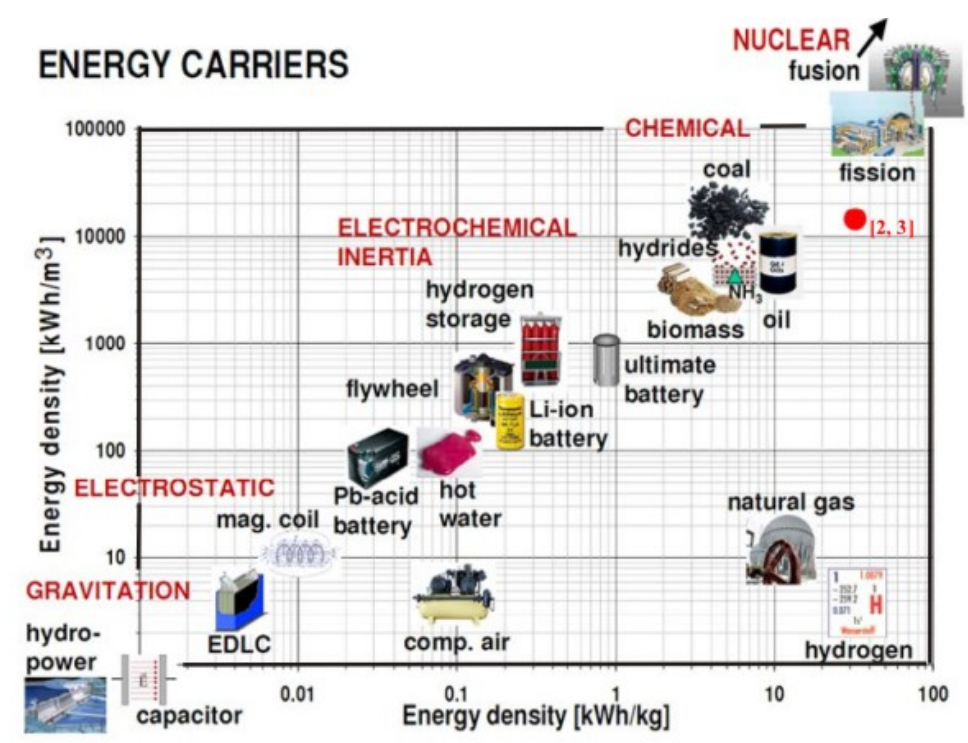

Figure 1. Data on volumetric (volume) and gravimetric (mass) energy densities for different energy carriers. 


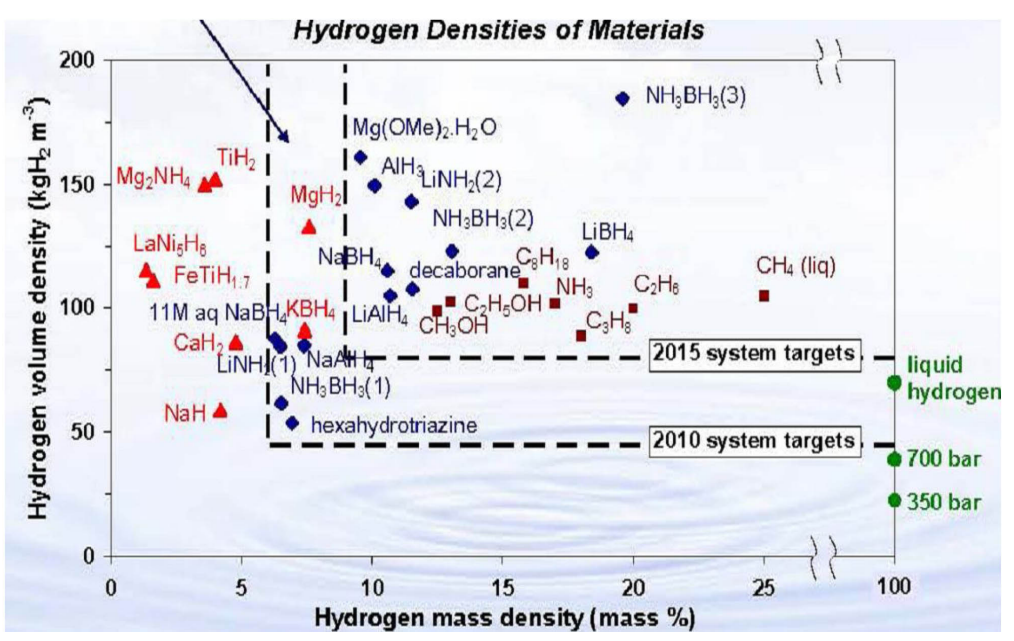

Figure 2. Correlation between volume and mass of hydrogen densities of various materials.

volumetric (volume) storage densities (capacities) of "reversible" hydrogen for 2010 (6.0 mass\% $\mathrm{H}_{2}$ (of the system mass), $45 \mathrm{~kg}\left(\mathrm{H}_{2}\right) / \mathrm{m}^{3}$ (system)) and for 2015 (9.0 mass\% $\mathrm{H}_{2}$ (of the system mass), $81 \mathrm{~kg}\left(\mathrm{H}_{2}\right) / \mathrm{m}^{3}$ (system)). These values are higher than the targets established by the E.U and/or Japan. The additional symbol (the large red circle) corresponds to the analytical data [2] [3] on the molecular solid hydrogen intercalated into the hydrogenated graphite nanofibers (GNFs); those are related to the extraordinary data [4]-[12] (being under consideration in this paper). The 2017 targets [16] are of 5.5 mass\% $\mathrm{H}_{2}$ (of the system mass) and $40 \mathrm{~kg}\left(\mathrm{H}_{2}\right) / \mathrm{m}^{3}$ (system). As has been noted in [18] [19]: 1) “... to realize a compact and energy efficient hydrogen storage is a key technology” [18]; 2) “... breakthroughs in hydrogen densities are strongly required” [18]; 3) it is necessary "to find a breakthrough technology” [19].

\section{Some of the Materials under Study in CoE's}

There are shown in Figure 3 the prognosis data [18] (amended in January 2011) on market entry of fuel cell powered vehicles (FCVs) and hydrogen charging stations. Particularly, it is shown that year 2015 can be related to the target commercialization start of FCVs to general public (see further shown Items 6 and 7-the Toyota announcement-2014), and Year 2025-to an increase numbers of FCVs and hydrogen stations based on profitable business. As is also shown (Figure 3, [18]), the present time is a very suitable (in the plan of the market entry prognosis) for such a developments. In this connection, it's also expedient to note about a number of communications of 2013-2014 (in Internet) on the nowadays market situation, relevance to fuel-cell electrical vehicles (FCVs) and hydrogen charging stations, for instance the following.

\subsection{Hyundai's Fuel-Cell Vehicle Could Be a Massive Success. The Motley Fool}

Oct. 24, 2013: Hyundai isn't the only manufacturer in the race for FCVs. Toyota Motors, Daimler's Mercedes-Benz, BMW, and a number of other car companies have spent billions in fuel-cell technology, and are all competing to see who can be the first to market with a consumer-friendly FCV.

\subsection{Hydrogen and Fuel Cells: GM-Honda Collaboration on Next-Generation Fuel Cell Technologies (03.07.2013)}

(http://www.netinform.net/h2/Aktuelles_Detail.aspx?ID=3285.) Goal is commercially feasible fuel cell and hydrogen storage in 2020 time frame.

On July 2, 2013: General Motors (NYSE: GM) and Honda (NYSE: HMC) announced a long-term, definitive master agreement to co-develop next-generation fuel cell system and hydrogen storage technologies, aiming for the 2020 time frame. The collaboration expects to succeed by sharing expertise, economies of scale and common sourcing strategies. Source: www.gm.com. 
KYUSHU UNIVERSITY

Fuel Cell Vehicle: Market Entry revised in June 2010 and amended in January 2011

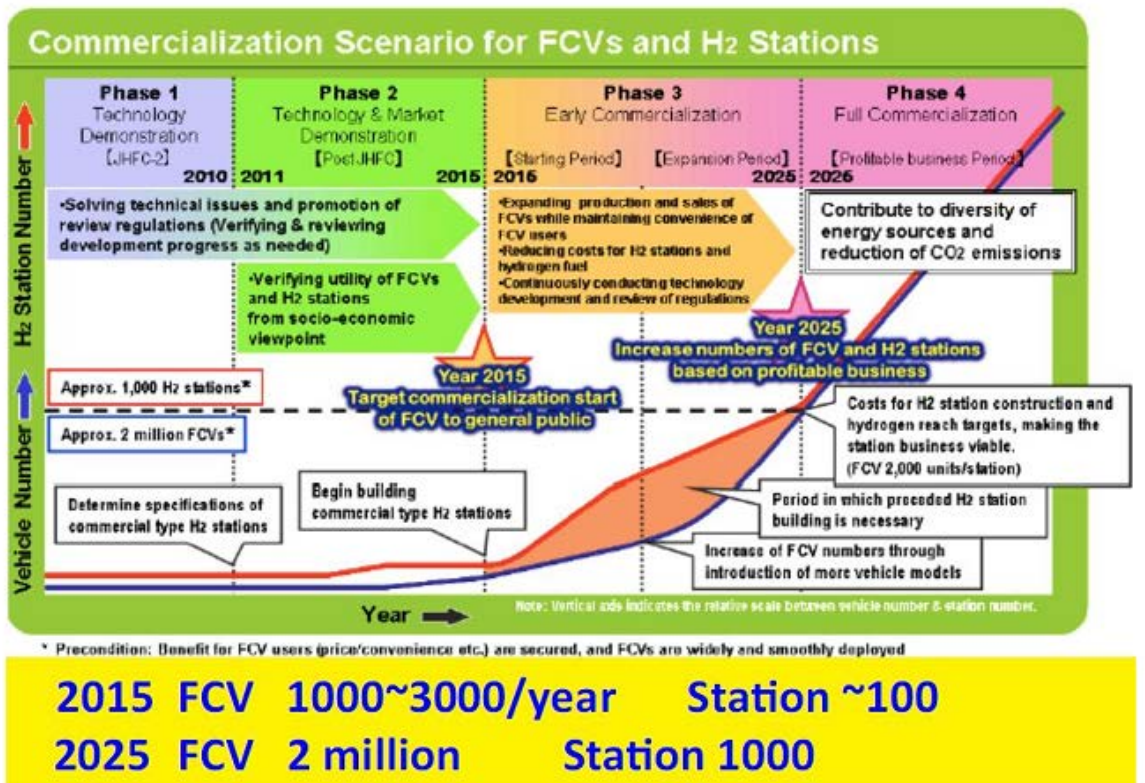

Figure 3. The prognosis data on market entry of fuel cell powered vehicles and hydrogen charging stations.

\subsection{Ballard Signs Long-Term Engineering Services Contract to Advance Volkswagen AG Fuel Cell Automotive Research Program Ballard Power}

Mar. 7, 2013: Ballard Power Systems has announced signing of an agreement with Volkswagen Group for a major Engineering Services contract to advance development of fuel cells for use in powering demonstration cars in Volkswagen's fuel cell automotive research program. The contract term is for 4 years, with an option for an extension. The expected contract value is in the range of \$60 - \$100 million.

\subsection{Hydrogen Fuel Research May Benefit from Shift in Auto Industry (Hydrogen Fuel News)}

Feb. 7, 2013: Ford, Daimler, and Nissan recently joined forces to make progress in the field of hydrogen fuel cell technology. Each of the companies has an ambitious goal in mind in terms of hydrogen transportation, but each has also been faces with challenges that threaten to derail these goals. The automakers decided to team up in order to overcome some of these challenges and introduce new standards to hydrogen fuel cell technology as a whole.

\subsection{US Department of Energy Launches New Hydrogen Fuel Initiative (Hydrogen Fuel News)}

May 23, 2013: Hydrogen fuel has become a major focus for the global auto industry and this focus is likely to transform the transportation sector around the world. As automakers put more emphasis on clean transportation, global markets are beginning to respond by supporting the promotion of hydrogen fuel in the transportation sector. Much of this support comes in the form of governments working to establish a working hydrogen fuel infrastructure that will be capable of supporting a new generation of fuel cell vehicles.

\subsection{As Is Noted in "CHFCA Weekly Fuel" of January 2014, Toyota Unveils Zero-Emissions Hydrogen Fuel-Cell "Car of the Future" for Sale Next Year (Think Progress)}

Toyota announced the launch of a hydrogen-powered fuel-cell car in the US next year at the annual Consumer 
Electronics Show (CES) in Las Vegas. The car, which resembles the popular Corolla, is yet to be named, but like the birth of a royal child it's the pedigree that counts—and Toyota is the largest auto manufacturer in the world.

\subsection{As Is Noted in "CHFCA Weekly Fuel” of January 2014, Toyota Touts Hydrogen Fuel Vehicles despite Criticism (The Detroit News)}

A top US Toyota Motor Corp. executive strongly stood by its focus on hydrogen fuel cell vehicles, defending their safety and dismissing criticism from the top executives at Tesla Motors, Nissan Motor Co. and others. "I realize there is no shortage of naysayer regarding the viability of this technology and the infrastructure to support it," said Bob Carter, senior vice president for automotive operations, Toyota Motor Sales USA Inc.

In connection with this, it is also expedient to take into account the long-term corporation (partnership) of Shell and General Motors Companies, relevance to hydrogen charging stations and fuel cell electrical vehicles, for instance:

1) July 2011: "The hydrogen infrastructure for automobiles is economically viable and do-able," said Larry Burns, Ph.D., General Motors Vice President, Research \& Development and Strategic Planning... Shell Hydrogen has been developing hydrogen and fuel cell businesses since 1999

www.minichamps.ru/2011/general-motors-shell-fuel-up-on-hydrogen-in-los/angeles.

2) It was installed in November 2007 by Shell and General Motors to provide a venue for demonstrations to federal lawmakers and officials. Hydrogen fuel cells have long been touted as the next great energy revolution: www.thelivingmoon.com/41pegasus/02files/Alternate_Fuel_Shell_Oil_Hydrogen.html.

3) November 2004: The hydrogen-dispensing pump is the first installed at a public gas station in the country, according to officials from Shell Hydrogen and General Motors Corp., who will team up today to... Virtually all the major auto manufacturers have prototype vehicles that run on fuel cells and are refining the technology: www.washingtonpost.com/wp-dyn/articles/A38168-2004Nov9.html.

4) Washington DC, March 5, 2003-General Motors Corp. and Shell Hydrogen are combining resources to help make hydrogen fuel cell vehicles a commercially viable reality, the two announced today. "The partnership brings together two leaders in hydrogen energy and transportation to take a coordinated, comprehensive approach," said Donald Huberts, chief executive officer of Shell Hydrogen. "By combining GM's expertise in vehicle technology with Shell's leadership in refueling technologies, the initiative represents an important step forward in the commercialization of hydrogen fuel cell vehicles"

http://www.wec.org/news/shell-gm-partner-to-make-hydrogen-fuel-cell-vehicles-a-reality.

\subsection{Shell Predicts the End of the Gas Guzzler by 2070. The New Zealand Herald (2014)}

Shell has released a report predicting the end of petrol-powered cars will be in 2070. The oil giant have compiled a 46-page report, using the progress in automotive fuel technology and economic scenarios as a basis for their prediction of all petrol cars becoming a thing of the past by 2070 .

In the present paper are considered, in the light of a constructive critical analysis [2] [3] of a number of data [4]-[12] [20]-[22], some fundamental aspects—open questions, relevant to developing, may be, within several years time frame, of a key breakthrough technology of a compact and energy efficient hydrogen storage in hydrogenated graphite nanofibers (GNFs).

\subsection{The Northeastern University (NU) Group [4]-[8] Hydrogen Storage Activity}

As was noted in [20] (2002) by Maeland, whose two works were cited in [4] (Ref. [1] (1978) and Ref. [4] (1981) in it), at the 1996 fall meeting of the US Materials Research Society (MRS), held in Boston, Massachusetts, Rodriguez and Baker of Northeastern University (NU), Boston, presented a paper in which they claimed the development of a "super" hydrogen storage nanomaterial. The material, graphite nanofibers (GNFs), discovered by Baker back in 1972 was claimed to be capable of storing up to 30 liters of gaseous hydrogen $\left(\mathrm{H}_{2}\right)$ per gram of nanofibers of the herringbone-like structure (Ref. [50] (1996) and Ref. [51] (1997) in [20]), i.e. about 73 mass\% (of the graphite-hydrogen system mass) corresponding to formula CH32. The graphite nanofibers (GNFs) were preparing by reacting hydrocarbons with carbon monoxide on catalytic particles of bi- or tri-metallic nickel or iron. Hydrogen uptakes were determined by exposing, in a system of known volume, a purified GNF bundle 
(batch-like) sample to molecular gaseous hydrogen at room temperature, and observing the drop in pressure over a 24 hour period from an initial value of 11.2 MPa [4] (Ref. [61] (1998) in [20]). Three of the herringbone-like structure samples, according to [4], take up hydrogen to give the hydrogen adsorption data of $62 \pm 5$ mass\% (but not 73 mass\%, as it was declared in the earlier talks $(1996,1997)$ ), two of the platelet-like structure samples take up hydrogen to give the hydrogen adsorption data of 46 and 54 mass\%, and the tubular-like structure sample11 mass\%. Four of the herringbone-like structure hydrogenated samples, according to [4], released the most of the stored hydrogen (at room temperature for $5-10 \mathrm{~min}$ ) to give the reversible hydrogen desorption data of $48 \pm$ 5 mass\%; the rest part of the stored hydrogen was released at higher temperatures (under temperature-programmed desorption examination) to give the irreversible hydrogen desorption data of $14 \pm 5$ mass\%. The results reported by Rodriguez and Baker immediately caused controversy. Michal Heben of the National Renewable Laboratory in Denver, Colorado, USA, pointed out that the highest ratio of hydrogen to carbon found in Nature is 4/1 $\left(\mathrm{CH}_{4}\right)$ and corresponds to 25 mass\% and expressed skepticism (Ref. [51] (1997) in [20]) of the results and attempts to verify the results of Rodriguez and Baker. Ahn et al. (Ref. [52] (1998) in [20]) measured hydrogen adsorption and desorption at $300 \mathrm{~K}$ on graphite nanofibers (GNFs) and reported that the absolute level of hydrogen desorption from these materials were typically less than $0.025 \mathrm{H} / \mathrm{C}(0.2$ mass\%) which is comparable to other forms of carbon. Jarvi et al. (Ref. [53] (1999) in [20]) reported very low hydrogen storage capacity at $303 \mathrm{~K}$, comparable to activated carbon, for graphite nanofibers (GNFs) prepared by catalytic decomposition of ethylene over nickel, iron, copper/nickel and alumina/magnesia catalysts and concluded that they were unlikely storage materials for hydrogen. However, they left the door open by stating that subtle processing effect might convert inactive materials into effective hydrogen sorbents (as has been recently shown in analytical studies [2] [3], and is considered in the present analytical study). As was also noted in [20], the announcement at the MRS meeting did not escape the automakers and Daimler-Chrysler began an evaluation study with the NU group of these "super" hydrogen storage materials. Later, however, Daimler-Chrysler ended their participation in the study. Then, Ford Motor Company was supporting the NU group (Ref. [54] (1999) in [20]). The NU group was also supported by the DOE in USA (Ref. [55] (1998) in [20]), but the support was terminated presumably because of the un-willingness of Rodriguez and Baker to share their GNF samples with other DOE laboratories for examination. More detailed description of the situation was done by Jennifer Babson, a freelance writer in Boston, who interviewed (in November 1997) Rodriguez and Baker; see two 10/25/97 articles from the Economist on hydrogen fuel. This un-willingness to submit samples to other investigations had continued to fuel the controversy and prompted Dr. Gary Sandrock, a well known expert in the field of hydrogen storage materials, to publically call on Rodriguez to submit samples to others for a "Real-Word Test" of her nanofiber materials (Ref. [56] (1998) in [20]). It, however, had not been done (so far as we know) up to 2005 [21] [22], despite the fact that Rodriguez and Baker were issued two related US patents of 1997 ("Storage of hydrogen in layered nanostructures") [6] and 2000 ("Method for introducing hydrogen into layered nanostructures") [7] and had thus secured protection for their process. As can be shown, the negative test-results [21] [22], with respect to [4]-[12] data (i.e., both for Rodriguez-Baker et al. data [4]-[8], and for Gupta et al. ones [9]-[12]), could be caused by using in [21] [22] the non-adequate GNF samples (including samples supplied for this test by Rodriguez and Baker themselves). The work of the NU group had been presented in a number of talks (Refs. [58]-[60] (1999) in [20]) and in two yearly cited (up to nowadays) articles in the Journal of Physical Chemistry of 1998 [4] and 1999 [5]. Article [4] has been cited (from 1998) 168 times in Scopus; the most recent citing is in two articles of 2013 [23] [24]. Article [5] has been cited (from 1999) 196 times in Scopus; the most recent citing is in two articles of 2013 [25] [26].

Unlike [4] [5] (1998, 1999), the Gupta et al. papers [9]-[11] [12] (2000-2004, 2006) have not been discussed and/or cited so much, despite of the situation that, as far as we know, only experimental results [9]-[12] confirm (and reproduce, in an essential degree) the extraordinary experimental data [4]-[8]. And as far as we know, both authors [4]-[8] (1998-2000, 2005) and authors [9]-[12] (2000-2004, 2006) have never crossed out their extraordinary experimental results. Nevertheless, authors [4] (1998) had done some corrections (and/or modifications) in [5] (1999) of their original adsorption-desorption data. Baker (in [8] (2005)) had modified the reversible hydrogen adsorption-desorption data [4] (for the herringbone-like structure GNF samples) up to value of " $40 \%$ by mass of molecular hydrogen per gram of carbon" that corresponds to 29 mass\% of hydrogen (of carbon-hydrogen system mass), instead of $48 \pm 5$ mass\% quantity declared in [4]. In article of Lueking et al. [27] (2004), where Rodriguez and Baker were co-authors, it was noted the quantity of 67 mass\%, relevance to [4] [6] data (for the herringbone-like structure GNF samples), and the quantity up to 40\%, relevance to [5] [7] data (for the 
herringbone-like structure GNF samples). The graphite nanofibers (GNFs) possessing a herringbone-like structure and a high degree of defects (dislocations) were found [27] to exhibit the best performance for hydrogen storage resulted in 3.8 mass\% release after exposure at 69 bar and room temperature (for $10 \mathrm{~h}$ ). This result is in contrary with data [4]-[8]. But, as was stressed in [27], the "herringbone" graphite nanofibers (GNFs) used in that investigation were produced from a different catalyst formulation than that used in [4] and [5]. Furthermore, as was also stressed in [27], the hydrogenation adsorption/desorption protocol followed there was not the same as that used in [4] and [5]. It is necessary to emphasize that the extraordinary experimental results [4]-[12] have not been reproduced by other research teams worldwide [20]-[22] [27]-[30]. But the rather known authors [4]-[12] (see, for instance, information about them in Scopus and/or ScienceDirect.com Internet programs) have not definitely crossed out their data (as far as we know). Some of these works [4] [5] have been yearly cited (up to nowadays). On the other hand, the physics of such results [4]-[12] has been developed (in an essential degree) in analytical studies [2] [3] [31]-[33]. Therefore, there are serious reasons to assume (following to [34] [35]) that experimental works [4]-[12] have contained some "know-how" methodological and/or technological elements. It is under a consideration in the present analytical study.

\section{Some Fundamental Open Questions of the Considered Problem}

\subsection{On Thermodynamic Stability and Related Characteristics of Some Hydrogenated Graphene Layers Nanostructures: Relevance to the Hydrogen Storage Problem}

The analytical study [2] [3] is devoted to consideration of the thermodynamic stability, and related thermodynamic characteristics of the following graphene layers systems: 1 ) double-side hydrogenated graphene of composition CH (theoretical graphene [36] (Figure 4)) and experimental graphene [37]; 2) theoretical single-side hydrogenated graphene of composition $\mathrm{CH}$; 3) theoretical single-side hydrogenated graphene of composition $\mathrm{C}_{2} \mathrm{H}$ (graphene); 4) experimental hydrogenated epitaxial graphene, bilayer graphene and a few layer graphene on $\mathrm{SiO}_{2}$ or other substrates; 5) experimental and theoretical single-external side hydrogenated single-walled carbon nanotubes, and experimental hydrofullerene $\mathrm{C}_{60} \mathrm{H}_{36} ; 6$ ) experimental single-internal side hydrogenated (up to $\mathrm{C}_{2} \mathrm{H}$ or $\mathrm{CH}$ composition) graphene nanoblisters with intercalated high pressure $\mathrm{H}_{2}$ gas inside them, formed on a surface of highly oriented pyrolytic graphite or epitaxial graphene under the atomic hydrogen treatment; and 7) experimental hydrogenated graphite nanofibers-multigraphene with intercalated solid $\mathrm{H}_{2}$ nanoregions of high density inside them [2] [3], relevant to solving the current problem of the hydrogen storage in fuel-cell-powered vehicles and other clean energy applications. It is expedient to note [2] [3] that there are a number of fundamental open questions in this field to be further studied.

The Figure 4 shows the diamond-like distorted hexagonal network with carbon in $\mathrm{sp}^{3}$ hybridization [36], the carbon atoms are shown in gray and the hydrogen atoms in white.

\subsection{Determination of Thermodynamic Characteristics of Graphene Hydrides}

Some theoretical, experimental and semi-empirical results [3] [36]-[41] of determination of thermodynamic characteristics of graphene hydrides, including determination of the energy of formation of graphene hydrides from graphene and atomic gaseous hydrogen, the energy of breaking-down of $\mathrm{C}-\mathrm{H} \mathrm{sp}{ }^{3}$-bonds $(\Delta \mathrm{H}(\mathrm{C}-\mathrm{H}))$ in graphene hydrides, the energy of formation of graphene hydrides from atomic gaseous carbon and atomic gaseous hydrogen, the energy of breaking-down of $\mathrm{C}-\mathrm{C} \mathrm{sp}^{3}$-bonds $(\Delta \mathrm{H}(\mathrm{C}-\mathrm{C})$ ) in graphene hydrides, and some other characteristics are considered (Table 1) from [3].

The critical comparison of the theoretical and experimental quantities, resulting in determination of the errors of the theoretical evaluations, are also included in [3]. In the light of the analytical results [3], two open questions formulated by K.S. Novoselov, A.K. Geim et al. (2009) [37] are considered, namely as:

1) Is the theoretical graphene $(\mathrm{CH})[36]$ "the until-now-theoretical material"?

2) May the experimental hydrogenated graphene $(\mathrm{CH})$ [37] have "a more complex hydrogen bonding than the one suggested by theory [36]"?

Two other fundamental open questions [3] are also discussed, namely as:

3) Can hydrogenated graphene layers nanostructures (graphene hydrides) with a high energy of C-C $\mathrm{sp}^{3}$-bonds close to that for graphene exist?

4) Can a solid (or liquid) molecular hydrogen nanophase be intercalated into hydrogenated graphite nanofibers. 


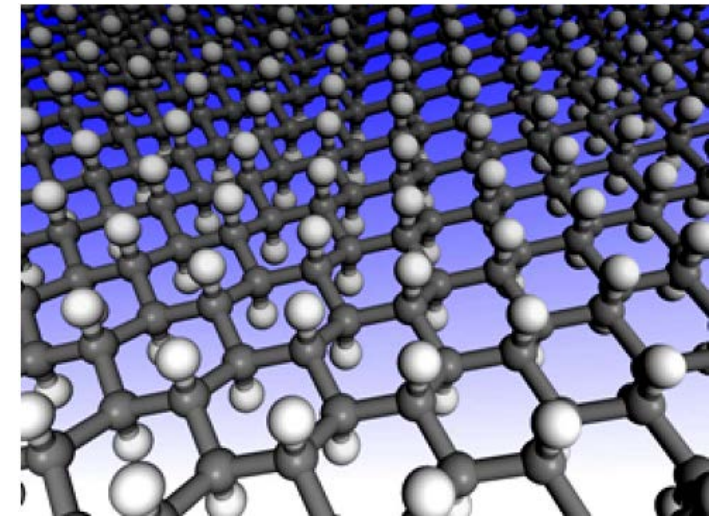

Figure 4. The theoretical graphene structure in chair configuration.

Table 1. Analytical and other characteristics.

\begin{tabular}{|c|c|c|c|c|c|}
\hline & & Val & antity (analyti & & \\
\hline & $\begin{array}{c}\Delta \mathrm{H}(\mathrm{C}-\mathrm{H}) \\
(\mathrm{eV})\end{array}$ & $\begin{array}{l}\Delta \mathrm{H} \text { (bind.) } \\
\quad(\mathrm{eV})\end{array}$ & $\begin{array}{c}\Delta \mathrm{H}(\mathrm{C}-\mathrm{C}) \\
(\mathrm{eV})\end{array}$ & $\begin{array}{l}\Delta \mathrm{H} \text { (des.) } \\
(\mathrm{eV})\end{array}$ & $\begin{array}{c}\mathrm{K}^{0} \text { (des.) } \\
\left(\mathrm{s}^{-1}\right)\end{array}$ \\
\hline Graphene [36] & $(2.5 \pm 0.1)$ an. & 6.56 & (2.7) an. & (2.5) an. & \\
\hline Graphene [39] & 1.50 & 5.03 & (2.35) an. & (1.5) an. & \\
\hline $\begin{array}{c}\text { Graphene [38] } \\
\text { Graphene [38] an. }\end{array}$ & $\begin{array}{l}2.46 \pm 0.17 \\
2.46 \pm 0.17\end{array}$ & & & $\begin{array}{l}2.46 \pm 0.17 \\
2.46 \pm 0.17\end{array}$ & $\begin{array}{c}(2.1 \pm 0.5) \times 10^{17} \\
2.0 \times 10^{15}\end{array}$ \\
\hline Graphene membrane [37] an. & $\begin{array}{l}2.5 \pm 0.1 \\
2.6 \pm 0.1\end{array}$ & & & $\begin{array}{l}2.5 \pm 0.1 \\
2.6 \pm 0.1\end{array}$ & $\begin{array}{l}7 \times 10^{12} \\
5 \times 10^{13}\end{array}$ \\
\hline Graphene epitaxial [37] an. & $\begin{array}{l}1.84 \\
1.94\end{array}$ & & & $\begin{array}{l}1.84 \\
1.94\end{array}$ & $\begin{array}{l}7 \times 10^{12} \\
5 \times 10^{13}\end{array}$ \\
\hline $\begin{array}{l}\text { Graphene epitaxial, } \\
\text { TDS \#1 [37] an. }\end{array}$ & & & & $0.6 \pm 0.3$ & $2 \times 10^{7}$ \\
\hline $\begin{array}{l}\text { Graphene epitaxial, } \\
\text { TDS \#2 [37] an. }\end{array}$ & & & & $0.6 \pm 0.3$ & $1 \times 10^{6}$ \\
\hline $\begin{array}{c}\text { Graphene epitaxial, } \\
\text { TDS \#3 [37] an. }\end{array}$ & & & & $0.23 \pm 0.05$ & 2.4 \\
\hline Graphene [39] & & 7.40 & (4.93) an. & & \\
\hline Graphene $^{*}[31]-[33]$ & 2.6 & 9.95 & 4.9 & 2.6 & \\
\hline Graphite [31]-[33] & & $7.41 \pm 0.05$ & $4.94 \pm 0.03$ & & \\
\hline Diamond [31]-[33] & & $7.38 \pm 0.04$ & $3.69 \pm 0.02$ & & \\
\hline Hydrofullerene $\mathrm{C}_{60} \mathrm{H}_{36}[40]$ & $2.64 \pm 0.01$ & & & & \\
\hline $\begin{array}{l}\text { Hydrogenated carbon } \\
\text { nanotubes }\left(\mathrm{C}_{2} \mathrm{H},[41]\right)\end{array}$ & $2.5 \pm 0.2$ & & & & \\
\hline
\end{tabular}

\subsection{A Treatment \& Interpretation of Some Recent STM, STS, HREELS/LEED, PES, ARPS and Raman Spectroscopy Data on Hydrogen Sorption with Epitaxial Grapheme}

Herein, some results of the thermodynamic analysis [3] of the data [42]-[46] on hydrogen sorption with epitaxial graphene are presented in Table 2, Table 3. In the framework of the formal kinetics approximation of the first order rate reaction, the characteristic quantities for the processes [42]-[46] of hydrogen sorption (the rate constant $(\mathrm{K}$ (des.) $=1 / 0.63$ (des.)), the activation energy $(\Delta \mathrm{H}$ (des.)), the pre-exponential factor of the rate constant $\left(\mathrm{K}^{0}\right.$ (des.)) are determined.

Evaluation of the HREELS elastic peak FWHM of hydrogenated graphene on SiC substrate (SiC-D/ QFMLG-H) upon annealing is shown in Figure 5, where the uncertain annealing temperature is estimated to be $5 \%$, error bars represent the $\sigma$ variation of FWHM measured across the entire surface of several samples [44]. 
Table 2. Analytical results (from [3]).

\begin{tabular}{cccc}
\hline Materials & \multicolumn{3}{c}{ Values/quantities } \\
\cline { 2 - 4 } & $\Delta \mathrm{H}(\mathrm{des})(\mathrm{eV})$ & $\mathrm{K}^{0}(\mathrm{des})\left(\mathrm{s}^{-1}\right)$ & $\tau 0.63$ (des.) $553 \mathrm{~K}(\mathrm{~s})$ \\
\hline Graphene flakes/SiO ${ }_{2}[42]$ & $0.11 \pm 0.07$ & 0.15 & 70 \\
Graphene/Ni [43] & & & 130 \\
HOPG [43] & & & 130 \\
(SiC-D/QFMLG-H) [44] & $0.7 \pm 0.2$ & $9 \times 10^{2}$ & \\
(SiC-D/QFMLG) [44] & $2.0 \pm 0.6$ & $1 \times 10^{6}$ & \\
\hline
\end{tabular}

Table 3. Some other analytical results (from [3]).

\begin{tabular}{|c|c|c|c|c|}
\hline \multirow{2}{*}{ Samples } & \multicolumn{4}{|c|}{ Values/quantities (analytical: an.) } \\
\hline & $\Delta \mathrm{H}$ (des.) I (eV) & $\mathrm{K}^{0}$ (des.) I $\left(\mathrm{s}^{-1}\right)$ & $\Delta \mathrm{H}$ (des.) II (eV) & $\mathrm{K}^{0}$ (des.) II $\left(\mathrm{s}^{-1}\right)$ \\
\hline 1LG-15W (grapheme) [45] & $0.6 \pm 0.2$ & $2 \times 10^{4}$ & $0.19 \pm 0.07$ & $3 \times 10^{-2}$ \\
\hline 2LG-15W (bi-graphene) [45] & & & $0.9 \pm 0.3$ & $1 \times 10^{3}$ \\
\hline 1LG-5W (grapheme) [45] & $0.15 \pm 0.04$ & $2 \times 10^{-2}$ & $0.31 \pm 0.07$ & $5 \times 10^{-1}$ \\
\hline 2LG-5W (bi-graphene) [45] & $0.50 \pm 0.15$ & $2 \times 10^{3}$ & $0.40 \pm 0.15$ & 1 \\
\hline HOPG [47], TDS-peaks I, II & $0.6 \pm 0.2$ & $1.5 \times 10^{4}$ & $1.0 \pm 0.3$ & $2 \times 10^{6}$ \\
\hline Graphene/SiC [46] & & & 3.6 & $2 \times 10^{14}$ \\
\hline $\begin{array}{c}\text { HOPG [48], TDS-peaks I, II } \\
\text { HOPG [48], TDS-peak I }\end{array}$ & $\begin{array}{c}2.4[48] \\
(2.4 \pm 0.5) \text { an. }\end{array}$ & $\left(2 \times 10^{10}\right)$ an & $4.1[48]$ & \\
\hline GNF [5] [11], TDS-peaks I, II & $(2.4 \pm 0.5)$ an. & & & \\
\hline
\end{tabular}

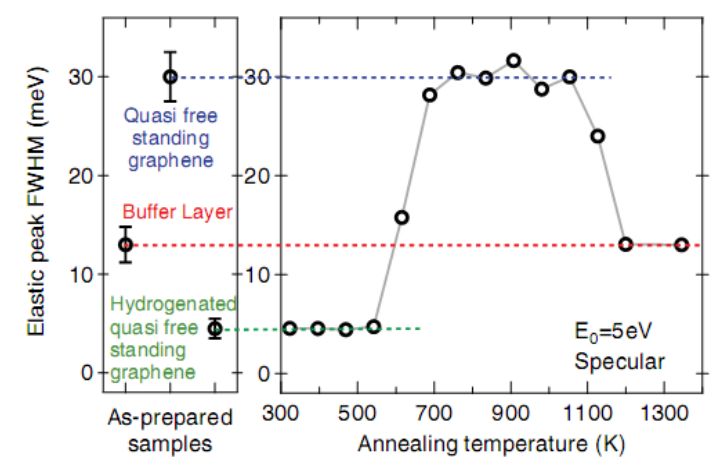

Figure 5. Evaluation of the HREELS elastic peak FWHM of hydrogenated graphene on SiC substrate upon annealing.

Some models (Figure 6) and characteristics [34] [35] of hydrogen chemisorption on graphite (on the basal and edge planes) have been used for interpretation of the results of data [42]-[46] treatment, in relation with the hydrogen storage problem. Schemes of some theoretical models of chemisorption of atomic hydrogen on graphite on the basal and edge planes [34] [35] are presented in Figure 6.

As it is shown in [2] [3], there are a number of fundamental open questions also in this field to be further studied.

\subsection{On the Physics of Intercalation of Hydrogen into Surface Graphene-Like Nanoblisters in Pyrolytic Graphite and Epitaxial Grapheme}

In the light of the analytical results [3], the physics of the spontaneous process ([47]-[50] and others) of intercalation of gaseous molecular hydrogen of a high pressure into nanoblisters - the surface nano-size bulges with monolayer graphene-like "walls", those being formed (at definite conditions of hydrogenation in atomic gaseous hydrogen) on a surface of highly oriented pyrolytic graphite (Figure 7, Figure 8) and epitaxial graphene (Figure 9, Figure 10). A fundamental open question [3] [51] namely as "Can gaseous atomic hydrogen 
<smiles>C1=CC2CCC3C4C=CCC4C=CC3C2CC1</smiles>

$\mathrm{E}$

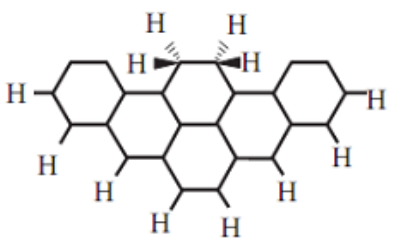

G

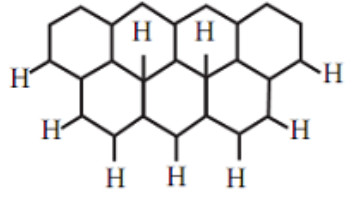

F

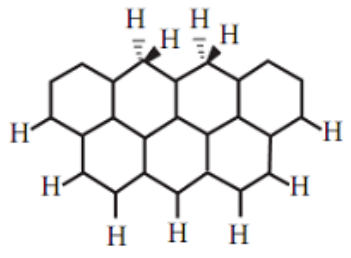

$\mathrm{H}$

Figure 6. Schemes of some theoretical models of chemisorption of atomic hydrogen on graphite on the basal and edge planes.
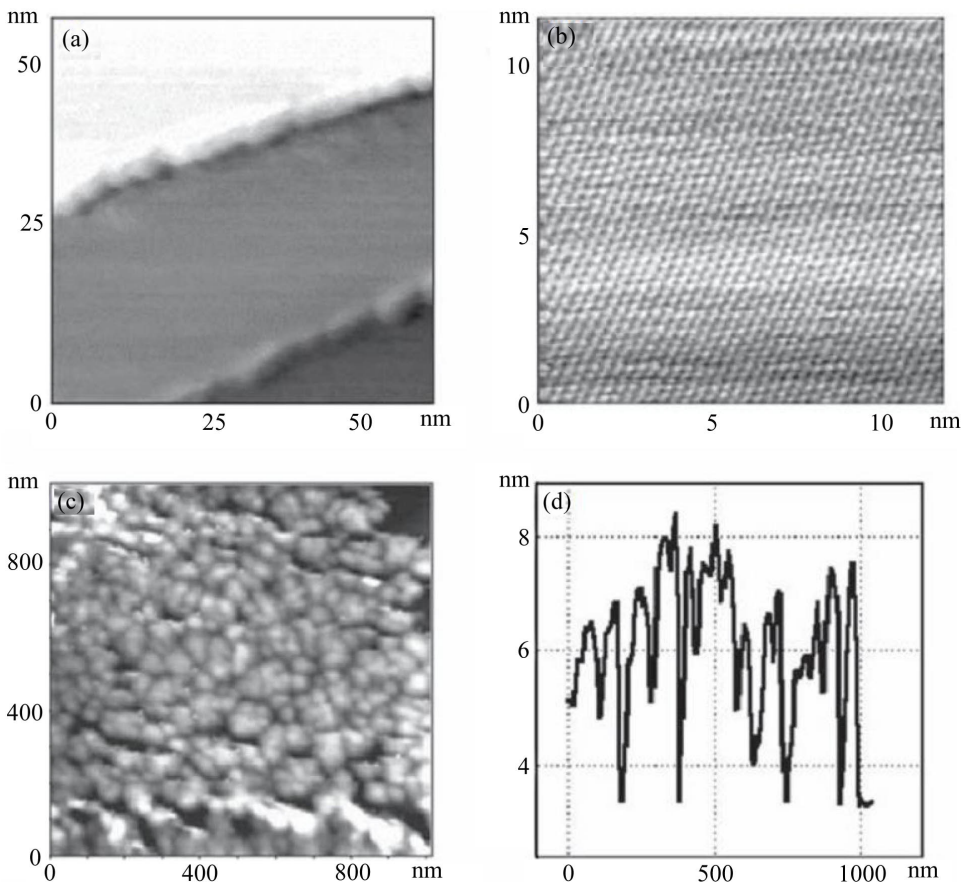

Figure 7. High resolution STM images of the untreated HOPG sample taken from varios areas of: (a) $60.8 \times 60.8 \mathrm{~nm}$; (b) $10.9 \times 10.9 \mathrm{~nm}$; (c) AFM image (area of $1 \times 1 \mathrm{~nm}$ ); (d) Surface height profile obtained from the AFM image reported in (c).

penetrate through a perfect graphene monolayer?” is also discussed.

On Figure 7 there are STM images of the untreated HOPG sample [49] (under ambient conditions) taken from areas of (a) $60.8 \times 60.8 \mathrm{~nm}$ and (b) $10.9 \times 10.9 \mathrm{~nm}$ (high resolution image of the square in image (a)). (c). AFM image (area of $1 \times 1 \mathrm{~nm}$ ) of the HOPG sample subjected to atomic hydrogen dose (D) of $1.8 \times 10^{16} \mathrm{H}^{0} / \mathrm{cm}^{2}$. (d) Surface height profile obtained from the AFM image reported in (c). The STM tunnel $V_{\text {bias }}$ and current are 50 - $100 \mathrm{mV}$ and 1 - $1.5 \mathrm{~mA}$, respectively.

Figure 8 shows a hydrogen storage efficiency of HOPG samples [49], desorbed molecular hydrogen (Q) versus dose (D) of atomic hydrogen exposure (Figure 8(a)) and STM image for $600 \times 600 \mathrm{~nm}$ area of the HOPG sample subjected to atomic hydrogen dose of $1.8 \times 10^{16} \mathrm{H}^{0} / \mathrm{cm}^{2}$, followed by hydrogen thermal desorption (Figure 8(b)). 

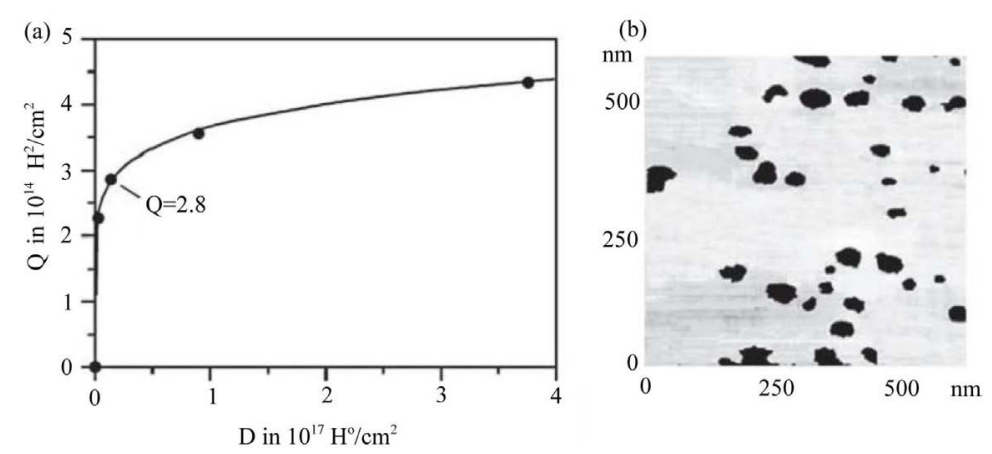

Figure 8. (a) Desorbed molecular hydrogen (Q) versus dose (D) of atomic hydrogen exposure; (b) STM image for $600 \times 600 \mathrm{~nm}$ area of the HOPG sample subjected to atomic hydrogen dose followed by hydrogen thermal desorption.

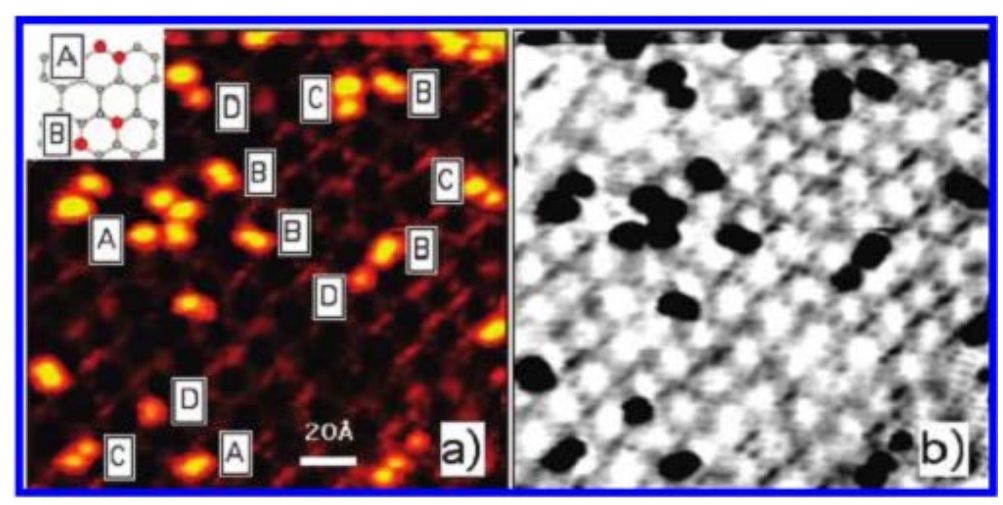

Figure 9. (a) STM image of hydrogenated graphene; (b) The same image as in (a) with inverted color scheme.

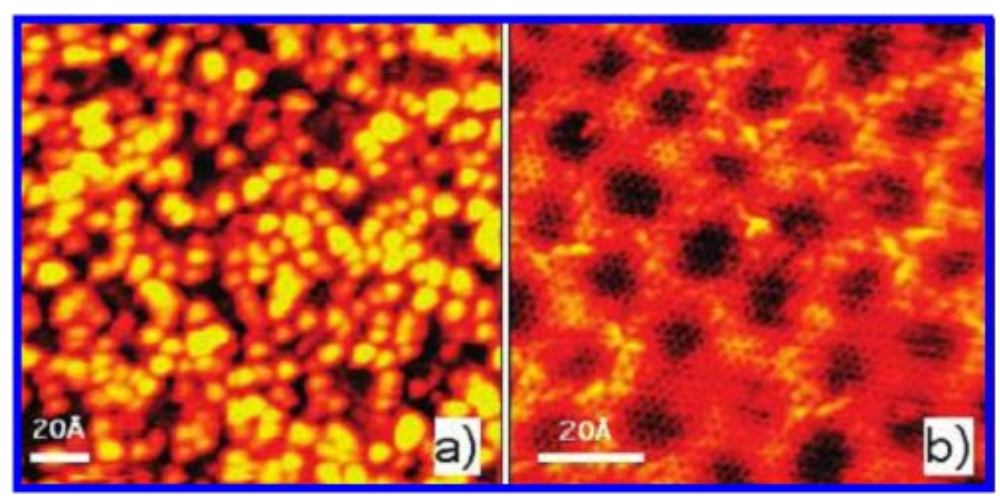

Figure 10. (a) STM image of the graphene surface after extended hydrogen exposure; (b) Large graphene area recovered from hydrogenation by annealing to $1073 \mathrm{~K}$.

Figure 9(a) presents a scanning tunneling microscopy (STM) image of hydrogenated graphene [50]. The bright protrusions visible in the image are atomic hydrogen adsorbate structures identified as A $=$ ortho-dimers, $\mathrm{B}=$ para-dimers, $\mathrm{C}=$ elongated dimers, $\mathrm{D}=$ monomers (imaging parameters: $V_{t}=-0.245 V_{t}, I_{t}=-0.26 \mathrm{nA}$ ). There is inset in (a): ortho- and para-dimer configuration on the graphene lattice (A and B, respectively). Figure 9(b) shows the same image as in Figure 9(a) but with inverted color scheme, giving emphasis to preferential hydrogen adsorption along the $6 \times 6$ modulation on the $\mathrm{SiC}(0001)-(1 \times 10$ surface $)$. Hydrogen dose at $T_{\text {beam }}=1600 \mathrm{~K}, t=5 \mathrm{~s}, F=10^{12}-10^{13}$ atoms $/ \mathrm{cm}^{2} \cdot \mathrm{s}$. 
Figure 10(a) presents the STM image of the graphene surface after extended hydrogen exposure [50]. The bright protrusions visible in the image are atomic hydrogen clusters (imaging parameters: $V_{t}=-0.36 \mathrm{~V}, I_{t}=-0.32$ $\mathrm{nA}$ ). Hydrogen dose at $T=1600 \mathrm{~K}, t=90 \mathrm{~s}, F=10^{12}-10^{13}$ atoms $/ \mathrm{cm}^{2} \cdot \mathrm{s}$. Figure 10(b) exibit a large graphene area recovered from hydrogenation by annealing to $1073 \mathrm{~K}$ (imaging parameters: $V_{t}=-0.38 \mathrm{~V}, I_{t}=-0.41 \mathrm{nA}$ ).

Authors of [51] noted that their test calculations show that the barrier for the penetration of a hydrogen atom through the six-membered ring of graphene is larger than $2.0 \mathrm{eV}$. Thus, they believe that it is almost impossible for a hydrogen atom to pass through the six-membered ring of graphene at room temperature (from a private communication with H.G. Xiang and M.-H. Whangbo). On the other hand, in the light of analysis [3] of a number of recent experimental studies, there is a real possibility that a hydrogen atom can pass through the graphene network at room temperature. This is the case of existing relevant defects in graphene, i.e., grain boundaries (particularly, the triple junctions of them) and/or vacancies.

\subsection{On the Physics of the Elastic \& Plastic Deformation of Graphene (Graphene-Like) Walls in Hydrogenated Graphite Nanofibers}

Herein, some results of the thermodynamic analysis [2] [3] of the unique (extraordinary) data [4]-[12] are considered. Mechanical behavior (the elastic and plastic deformation (Figure 11, Figure 12)) of the graphene (graphene-like) walls in graphite nanofibers (GNFs) under definite hydrogenation conditions are analyzed and interpreted, relevance to the hydrogen storage problem. There are a number of fundamental open questions also in this field to be further studied. Here, Figure 11 shows an increase in GNF width due to $\mathrm{H}_{2} \mathrm{O}$ adsorption [5].

Figure 12 shows the TEM of the dehydrogenated GNFs, by [11].

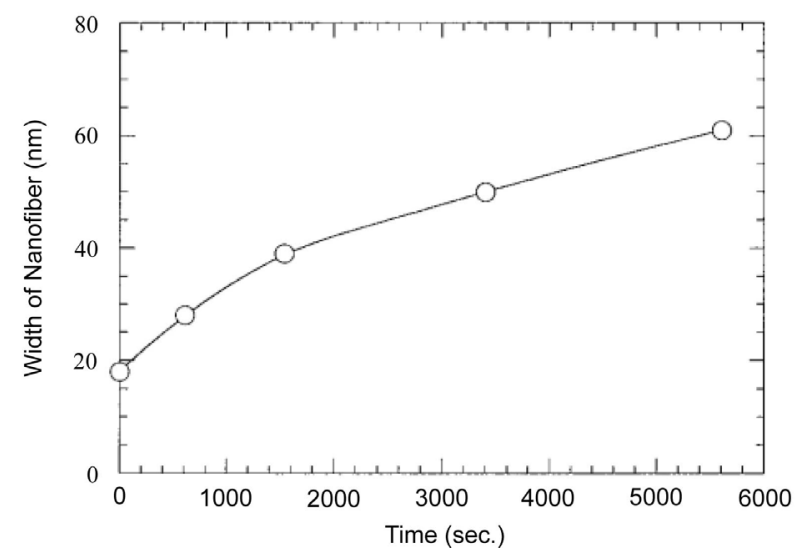

Figure 11. Increase in GNF width due to $\mathrm{H}_{2} \mathrm{O}$ adsorption.

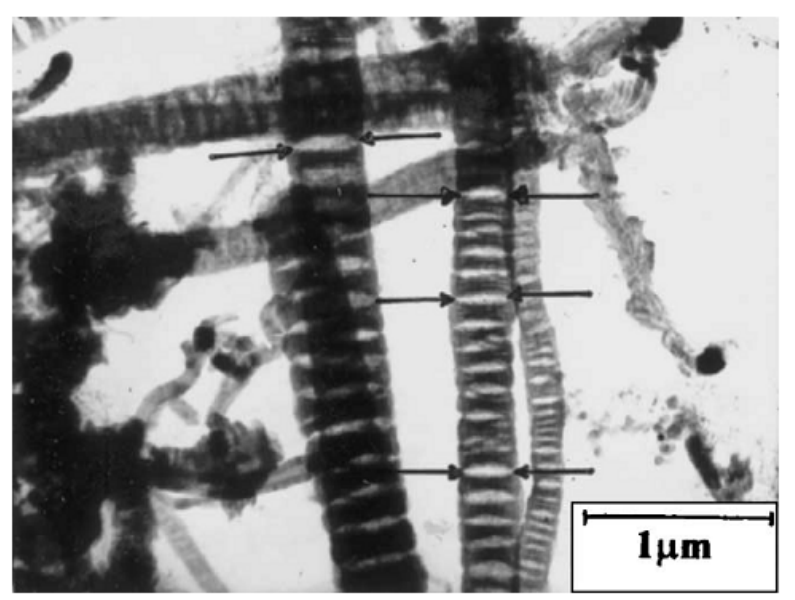

Figure 12. TEM of the dehydrogenated GNF. 


\subsection{On the Physics of Engineering of "Super" Hydrogen Storage Carbonaceous Nanomaterials, in the Light of Analysis of the Rodriguez-Baker Extraordinary Data and Some Others}

Herein, in the light of a constructive critical analysis (including the analytical results [2] [3]) of a complete set of the extraordinary experimental (nobody reproduced up to nowadays) data [4]-[12] and some related ones [52] [53], the physical fundamentals of developing of a key breakthrough technology of a compact and energy efficient hydrogen storage in hydrogenated graphite nanofibers (Figure 12, 1, 2) are considered. As far as we know, both authors [4]-[8] (1998-2005) and authors [9]-[12] (2000-2006) have never crossed out their extraordinary non-reproduced experimental results. On the other hand, article [4] has been cited (within 1998-2013) 168 times in Scopus, and article [5] - 196 times. But, as far as we know, nobody has analyzed and interpreted a complete set of [4]-[12] data. As is shown in the present study, the most recent negative test-results [21] [23], with respect to [4]-[12] data can be caused by using in [21] [22] the non-adequate GNF samples (including samples and regimes supplied for this test by Rodriguez and Baker themselves). Some ethical aspects of this long-term situation are discussed, as well.

\section{Conclusions}

1) As is shown in this work, in the light of analysis [2] [3], there are a number of fundamental open questions, relevance to developing of a key breakthrough technology of a compact and energy efficient hydrogen storage in hydrogenated graphite nanofibers (Figure 1, Figure 2), to be further studied.

2) These fundamental open questions [2] [3] [31]-[33] may be solved within several years, i.e., within the necessary time frame (Figure 3).

3) A constructive open discussion and, may be, a related international cooperation on solving the above considered open questions seems expedient, relevant to the promotion of further developments, particularly in the developing of basic grounds of a possible break-through in nanotechnology for hydrogen on-board storage and other clean energy applications [2] [3].

\section{Acknowledgements}

This work has been supported by the RFBR (Project \#14-08-91376 CT) and the TUBITAK (Project \# 213M523).

\section{References}

[1] Zuettel, A. (2011) Hydrogen the Future Energy Carrier. In: Materials of International Hydrogen Research Showcase 2011, University of Birmingham, Birmingham, 13-15 April 2011.

http://www.uk-shec.org.uk/ukshec/showcase/ShowcasePresentations.html

[2] Nechaev, Y.S. and Veziroglu, T.N. (2013) On Thermodynamic Stability of Hydrogenated Graphene Layers, Relevance to the Hydrogen On-Board Storage. The Open Fuel Cells Journal, 6, 21-39. http://dx.doi.org/10.2174/1875932701306010021

[3] Nechaev, Y.S. and Veziroglu, T.N. (2013) Thermodynamic Aspects of the Stability of the Graphene/Graphane/Hydrogen Systems, Layers, Relevance to the Hydrogen On-Board Storage Problem. Advances in Materials Physics and Chemistry, 3, 255-280. http://dx.doi.org/10.4236/ampc.2013.35037

[4] Chambers, A., Park, C., Terry, R., Baker, K. and Rodriguez, N.M. (1998) Hydrogen Storage in Graphite Nanofibers. Journal of Physical Chemistry B, 102, 4253-4256. http://dx.doi.org/10.1021/jp980114l

[5] Park, C., Anderson, P.E., Chambers, A., Tan, C.D., Hidalgo, R. and Rodriguez, N.M. (1999) Further Studies of the Interaction of Hydrogen with Graphite Nanofibers. Journal of Physical Chemistry B, 103, 10572-10581. http://dx.doi.org/10.1021/jp990500i

[6] Nelly, M., Rodriguez, N.M., Terry, R. and Baker, K. (1997) Storage of Hydrogen in Layered Nanostructures. US Patent No. 5653951.

[7] Nelly, M., Rodriguez, N.M., Terry, R. and Baker, K. (2000) Method for Introducing Hydrogen into Layered Nanostructures. US Patent No. 6159538.

[8] Baker, R.T.K. (2005) Encyclopedia of Materials: Science and Technology. Elsevier, Amsterdam, 932.

[9] Gupta, B.P. and Srivastava, O.N. (2000) Synthesis and Hydrogenation Behavior of Graphitic Nanofibers. Journal of 
Hydrogen Energy, 25, 825-830. http://dx.doi.org/10.1016/S0360-3199(99)00104-4

[10] Gupta, B.P. and Srivastava, O.N. (2001) Further Studies on Microstructural Characterization and Hydrogenation Behavior of Graphitic Nanofibers. International Journal of Hydrogen Energy, 26, 857-862. http://dx.doi.org/10.1016/S0360-3199(01)00021-0

[11] Gupta, B.K., Tiwari, R.S. and Srivastava, O.N. (2004) Studies on Synthesis and Hydrogenation Behavior of Graphitic Nanofibers Prepared through Palladium Catalyst Assisted Thermal Cracking of Acetylene. Journal of Alloys and Compounds, 381, 301-308. http://dx.doi.org/10.1016/j.jallcom.2004.03.094

[12] Gupta, B.P. and Srivastava, O.N. (2006) New Carbon Variants: Graphitic Nanofibers (Nano-Springs, Nano-Shoeckers) as Hydrogen Storage Materials. International Scientific Journal for Alternative Energy and Ecology, 5, 63.

[13] Suh, M.P., Park, H.J., Prasad, T.K. and Lim, D.W. (2012) Hydrogen Storage in Metal-Organic Frameworks. Chemical Reviews, 112, 782-835. http://dx.doi.org/10.1021/cr200274s

[14] Tozzini, V. and Pellegrini, V. (2013) Prospects for Hydrogen Storage in Graphene. Physical Chemistry Chemical Physics, 15, 80-89. http://dx.doi.org/10.1039/c2cp42538f

[15] Satyapal, S., Petrovic, J., Read, C., Thomas, G. and Ordaz, G. (2007) The U.S. Department of Energy’s National Hydrogen Storage Project: Progress towards Meeting Hydrogen-Powered Vehicle Requirements. Catalysis Today, 120, 246-256. http://dx.doi.org/10.1016/j.cattod.2006.09.022

[16] DOE (2012) Targets for Onboard Hydrogen Storage Systems for Light-Duty Vehicles. http://wwwl.eere.energy.gov/hydrogenandfuelcells/storage/\%20pdfs/targets_onboard_hydro_storage.pdf

[17] Fruchart, D. (2011) Large Scale Development of Metal Hydrides for Stationary and Nomad Hydrogen Storage Units. Which Are Potential Partners to Built Innovative Solutions for Sustainable and Clean Energy Systems? In: Materials of International Hydrogen Research Showcase 2011, University of Birmingham, Birmingham, 13-15 April 2011. http://www.uk-shec.org.uk/uk-shec/showcase/ShowcasePresentations.html

[18] Akiba, E. (2011) Hydrogen Related R\&D and Hydrogen Storage Materials in Japan. In: Materials of International Hydrogen Research Showcase 2011, University of Birmingham, Birmingham, 13-15 April 2011.

[19] Kim, J.W. (2011) Current Status of R\&D on Hydrogen Production and Storage in Korea. In: Materials of International Hydrogen Research Showcase 2011, University of Birmingham, Birmingham, 13-15 April 2011.

[20] Maeland, A.J. (2002) The Storage of Hydrogen for Vehicular Use-A Review and Reality Check. International Scientific Journal for Alternative Energy and Ecology, 1, 19-29.

[21] Rzepka, M., Bauer, E., Reichenauer, G., Schliermann, T., Bernhardt, B., Bohmhammel, K., Henneberg, E., Knoll, U., Maneck, H.E. and Braue, W. (2005) Hydrogen Storage Capacity of Catalytically Grown Carbon Nanofibers. The Journal of Physical Chemistry B, 109, 14979-14989. http://dx.doi.org/10.1021/jp051371a

[22] Reichenauer, G., Rzepka, M., Bauer, E., Schliermann, T., Bernhardt, B., Bohmhammel, K., Henneberg, E., Knoll, U., Maneck, H.E. and Braue, W. (2006) Hydrogen Storage Capacity of Catalytically Grown Carbon Nanofibers. Proceedings of International Conference on Carbon, The Robert Gordon University, Aberdeen, 6-21 July 2006.

[23] Ramos, A., Cameán, I. and García, A.B. (2013) Graphitization Thermal Treatment of Carbon Nanofibers. Carbon, 59, 2-32. http://dx.doi.org/10.1016/j.carbon.2013.03.031

[24] Camacho, R.M. and Guirado-López, R.A. (2013) Adsorption and Diffusion of Hydrogen on $\mathrm{C}_{60}$-Supported Pt $\mathrm{t}_{\mathrm{n}}$ Clusters. The Journal of Physical Chemistry C, 117, 10059-10069. http://dx.doi.org/10.1021/jp3113123

[25] Gao, Q., Qu, F.Y., Lin, H.M. and Zheng, W.T. (2013) A Simple Method to Synthesize Graphitic Mesoporous Carbon Materials with Different Structures. Journal of Porous Materials, 20, 983-988. http://dx.doi.org/10.1007/s10934-013-9677-3

[26] He, Z., Wang, S., Iqbal, Z. and Wang, X.Q. (2013) Hydrogen Storage in Hierarchical Nanoporous Silicon-Carbon Nanotube Architectures. International Journal of Energy Research, 37, 754-760. http://dx.doi.org/10.1002/er.2979

[27] Lueking, A.D., Yang, R.T., Rodriguez, N.M. and Baker, R.T.K. (2004) Hydrogen Storage in Graphite Nanofibers: Effect of Synthesis Catalyst and Pretreatment Conditions. Langmuir, 20, 704-721. http://dx.doi.org/10.1021/la0349875

[28] Ströbel, R., Garche, J., Moseley, P.T., Jörissen, L. and Wolf, G. (2006) Hydrogen Storage by Carbon Materials. Journal of Power Sources, 159, 781-801. http://dx.doi.org/10.1016/j.jpowsour.2006.03.047

[29] Yürüm, Y., Taralp, A. and Veziroglu, T.N. (2009) Storage of Hydrogen in Nanostructured Carbon Materials. International Journal of Hydrogen Energy, 34, 3784-3798. http://dx.doi.org/10.1016/j.ijhydene.2009.03.001

[30] Kowalczyk, P., Holyst, R., Terrones, M. and Terrones, H. (2007) Hydrogen Storage in Nanoporous Carbon Materials; Myth and Facts. Physical Chemistry Chemical Physics, 9, 1786-1792. http://dx.doi.org/10.1039/b618747a

[31] Nechaev, Y.S. (2012) Solid Hydrogen in Multigraphane Nanostructures. International Scientific Journal for Fundamental and Applied Physics, 1, 38-60.

[32] Nechaev, Y.S. (2011) On the Solid Hydrogen Carrier Intercalation in Graphane-Like Regions in Carbon-Based Nano- 
structures. International Journal of Hydrogen Energy, 36, 9023-9031. http://dx.doi.org/10.1016/j.ijhydene.2011.04.073

[33] Nechaev, Y.S. (2011) The High-Density Hydrogen Carrier Intercalation in Graphane-Like Nanostructures, Relevance to Its On-Board Storage in Fuel-Cell-Powered Vehicles. The Open Fuel Cells Journal, 4, 16-29. http://dx.doi.org/10.2174/1875932701104010016

[34] Nechaev, Y.S. (2006) The Nature, Kinetics, and Ultimate Storage Capacity of Hydrogen Storage by Carbon Nanostructures. Physics-Uspekhi, 49, 563-591. http://dx.doi.org/10.1070/PU2006v049n06ABEH002424

[35] Nechaev, Y.S. (2010) Carbon Nanomaterials, Relevance to the Hydrogen Storage Problem. Journal of Nano Research, 12, 1-44. http://dx.doi.org/10.4028/www.scientific.net/JNanoR.12.1

[36] Sofo, J.O., Chaudhari, A.S. and Barber, G.D. (2007) Graphane: A Two-Dimensional Hydrocarbon. Physical Review B, 75, Article ID: 153401. http://dx.doi.org/10.1103/PhysRevB.75.153401

[37] Elias, D.C., Nair, R.R., Mohiuddin, T.M.G., Morozov, S.V., Blake, P., Halsall, M.P., Ferrari, A.C., Boukhvalov, D.W., Katsnelson, M.I., Geim, A.K. and Novoselov, K.S. (2009) Control of Graphene’s Properties by Reversible Hydrogenation: Evidence for Graphane. Science, 323, 610-613. http://dx.doi.org/10.1126/science.1167130

[38] Openov, L.A. and Podlivaev, A.I. (2010) Thermal Desorption of Hydrogen from Graphane. Technical Physics Letters, 36, 31-33. http://dx.doi.org/10.1134/S1063785010010104

[39] Dzhurakhalov, A.A. and Peeters, F.M. (2011) Structure and Energetics of Hydrogen Chemisorbed on a Single Graphene Layer to Produce Graphane. Carbon, 49, 3258-3266. http://dx.doi.org/10.1016/j.carbon.2011.03.052

[40] Pimenova, S.M., Melkhanova, S.V., Kolesov, V.P. and Lobach, A.S. (2002) The Enthalpy of Formation and C-H Bond Enthalpy Hydrofullerene $\mathrm{C}_{60} \mathrm{H}_{36}$. The Journal of Physical Chemistry B, 106, 2127-2130. http://dx.doi.org/10.1021/jp012258x

[41] Bauschlicher Jr., C.W. and So, C.R. (2002) High Coverages of Hydrogen on (10.0), (9.0) and (5.5) Carbon Nanotubes. Nano Letters, 2, 337-341. http://dx.doi.org/10.1021/nl0202830

[42] Wojtaszek, M., Tombros, N., Garreta, A., Van Loosdrecht, P.H.M and Van Wees, B.J. (2011) A Road to Hydrogenating Graphene by a Reactive Ion Etching Plasma. Journal of Applied Physics, 110, Article ID: 063715. http://dx.doi.org/10.1063/1.3638696

[43] Castellanos-Gomez, A., Wojtaszek, M., Arramel, Tombros, N. and Van Wees, B.J. (2012) Reversible Hydrogenation and Bandgap Opening of Graphene and Graphite Surfaces Probed by Scanning Tunneling Spectroscopy. Small, 8, 1607-1613. http://dx.doi.org/10.1002/smll.201101908

[44] Bocquet, F.C., Bisson, R., Themlin, J.M., Layet, J.M. and Angot, T. (2012) Reversible Hydrogenation of DeuteriumIntercalated Quasi-Free-Standing Graphene on SiC (0001). Physical Review B-Condensed Matter and Materials Physics, 85, Article ID: 201401. http://dx.doi.org/10.1103/PhysRevB.85.201401

[45] Luo, Z.Q., Yu, T., Kim, K.J., Ni, Z.H., You, Y.M., Lim, S., Shen, Z.X., Wang, S.Z. and Lin, J.Y. (2009) ThicknessDependent Reversible Hydrogenation of Graphene Layers. ACS Nano, 3, 1781-1788. http://dx.doi.org/10.1021/nn900371t

[46] Watcharinyanon, S., Virojanadara, C., Osiecki, J.R., Zakharov, A.A, Yakimova, R., Uhrberg, R.I.G. and Johansson, L.I. (2011) Hydrogen Intercalation of Graphene Grown on 6H-SiC (0001). Surface Science, 605, 1662-1668. http://dx.doi.org/10.1016/j.susc.2010.12.018

[47] Hornekaer, L., Šljivančanin, Ž., Xu, W., Otero, R., Rauls, E., Stensgaard, I., Lægsgaard, E., Hammer, B. and Besenbacher, F. (2006) Metastable Structures and Recombination Pathways for Atomic Hydrogen on the Graphite (0001) Surface. Physical Review Letters, 96, Article ID: 156104. http://dx.doi.org/10.1103/PhysRevLett.96.156104

[48] Waqar, Z., Klusek, Z., Denisov, E., Kompaniets, T., Makarenko, I., Titkov, A. and Saleem, A. (2000) Effect of Atomic Hydrogen Sorption and Desorption on Topography and Electronic Properties of Pyrolytic Graphite. Electrochemical Society Proceedings, 16, 254-265.

[49] Waqar, Z. (2007) Hydrogen Accumulation in Graphite and Etching of Graphite on Hydrogen Desorption. Journal of Materials Science, 42, 1169-1176. http://dx.doi.org/10.1007/s10853-006-1453-1

[50] Balog, R., Jørgensen, B., Wells, J., Lægsgaard, E., Hofmann, P., Besenbacher, F. and Hornekær, L. (2009) Atomic Hydrogen Adsorbate Structures on Graphene. Journal of the American Chemical Society, 131, 8744-8745. http://dx.doi.org/10.1021/ja902714h

[51] Xiang, H.J., Kan, E.J., Wei, S.H., Gong, X.G. and Whangbo, M.H. (2010) Thermodynamically Stable Single-Side Hydrogenated Graphene. Physical Review B, 82, Article ID: 165425. http://dx.doi.org/10.1103/PhysRevB.82.165425 
Scientific Research Publishing (SCIRP) is one of the largest Open Access journal publishers. It is currently publishing more than 200 open access, online, peer-reviewed journals covering a wide range of academic disciplines. SCIRP serves the worldwide academic communities and contributes to the progress and application of science with its publication.

Other selected journals from SCIRP are listed as below. Submit your manuscript to us via either submit@scirp.org or Online Submission Portal.
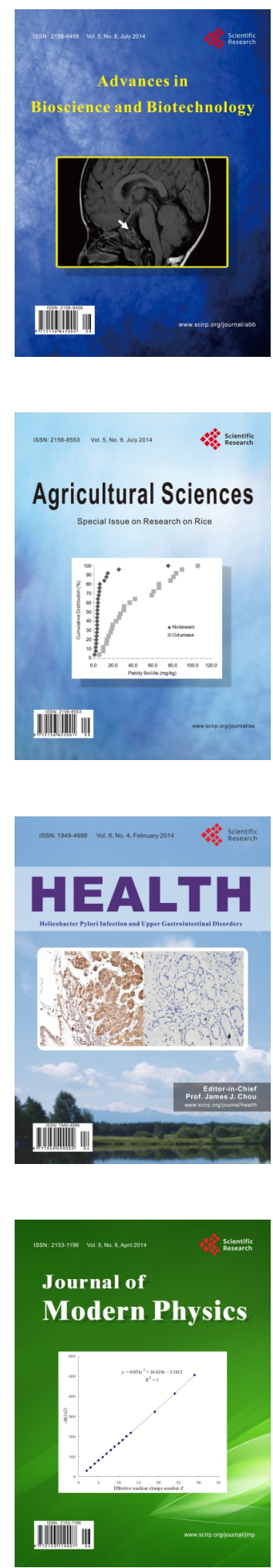
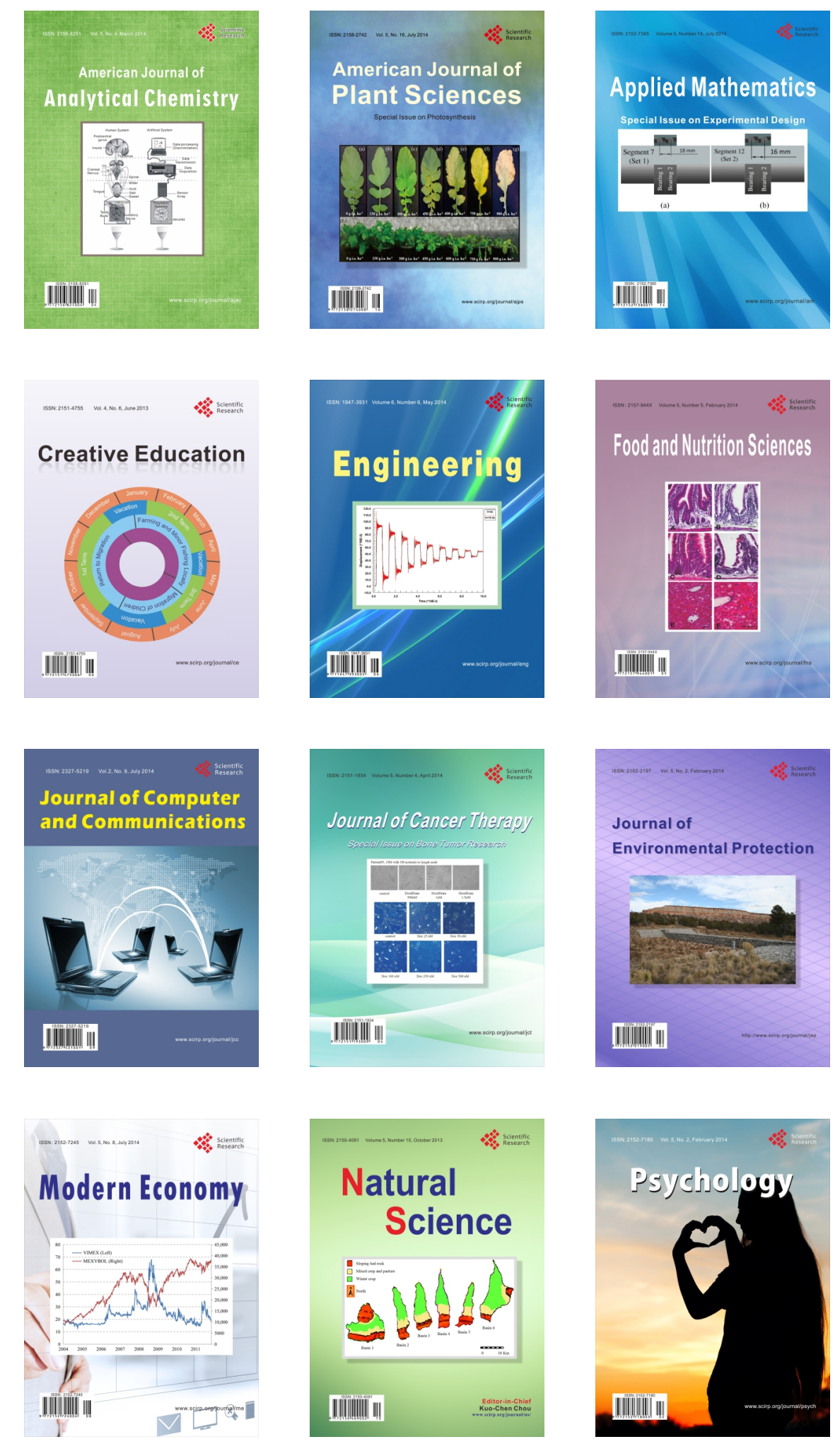